\title{
A New European Constitutional Patriotism for Habermas
}

\author{
Melis Menent \\ University of Sussex
}

\begin{abstract}
Habermas's interventions in German political affairs gave rise to the concept of constitutional Patriotism. His earlier theoretical work did not revisit the idea in any distinct manner. Moral Consciousness, I argue, has traces of a legal identity and universal morality. While interpreting Kohlberg's work, Habermas did not seek to tie the concept of citizenship or political identity into his account of Moral Consciousness. The concepts of political identity and a legal orientation come up, more recently and in a clearly observable manner, in Habermas's writings on Europe. His writings and speeches delivered on the idea of Europe before the Eurozone crises as well as those published and delivered after the crises refer to a strong sense of Constitutional Patriotism understood in the European sense. It is this idea that I would like to dwell on in this paper.
\end{abstract}

Keywords: identity, Europe, integration, legality, culture, international law, European law

"United Nations is the best hope of humanity" Habermas wrote. He as well as most of the neo-cosmopolitans who seek to bridge the gap between the universal ideals of human rights and political institutions considers the UN in the same light. It is an institution with a global scope. It claims to advocate the rights of every man on the virtue of being born. Rousseau wrote in the Social Contract that "human beings are born free and yet everywhere they are in chains. How did this change come about? I do not know.” Habermas also discusses the futility of the idea of human dignity which is associated with the concept of citizenship. He does this in the article titled "Human Dignity and the Realistic Idea of Human Rights" as well as in his recent book published titled The Crises of the European Union. Revisiting the same idea and revising the article for another publication shows the importance the concept of citizenship and universal human rights have for Habermas. Robert Fine wrote that the universal right content of human rights is inextricably linked to Cosmopolitanism (in “Jurgen Habermas' Theory of Cosmopolitanism”). Therefore, philosophers and social scientist have been pondering upon the ideal world and the world as it is for a long time. Kantianism, the social contract tradition, cosmopolitanism as well as critical theory are marked by the same quest.

"How, it will be asked, can a normative perspective recommending a cosmopolitan form of solidarity, with institutions to match, be reconciled with the existence of national communities in such a way as to achieve stability and justice?” writes Fine. The demands of universal moral norms and the discrepancy between them and the factual political existence of nation-states are the topic of more discussions on the issue than one: "As mankind, since the French Revolution, was conceived in the image of a family of nations, it gradually became evident that the people, and not the individual, was the image of man” (Arendt, 31). Any individual who found herself thrown out of those communities, such as the Jews during the Holocoust, would find herself thrown out

Melis Menent, Ph.D. candidate, Department of Philosophy, University of Sussex, UK; main research fields: Social and Political Thought. 
of the "family of nations altogether" (Arendt, 65). The idea of human rights derives its moral legitimacy from the concept of human dignity. It is this dignity which is lost at the loss of national citizenship, according to Arendt. Habermas's discussion of the link between citizenship and human dignity has the same connotations: "Human dignity still retains... the connotation of depending on the social recognition of status-in this case, the status of democratic citizenship.” In this article (which has originally been published in Metaphilosophy and has been revised for his last book on Europe), he challenges the core notion of citizenship as the conceptual link between human rights and human dignity. "Status of democratic citizenship" and "membership in a national community" as Arendt puts it point toward the need of a cosmopolitan form of citizenship. In Nussbaum's account, cosmopolitanism is discussed in the form of "Cosmopolitan Patriotism" as opposed to the theory of Constitutional Patriotism developed by Muller. The universal right content of human rights and human dignity bring it into juxtaposition with cultural norms which in some cases may contradict with human rights, and in some other cases, would be entangled with the national patriotic feelings of the citizens. While seeking to establish a cosmopolitan moral ideal, Habermas considers nation-states as the foremost obstacles before this. The theory of constitutional patriotism, however, takes this one step further and establishes national attachments as the most distinct obstacle before it.

Apart from the quest that sociology and philosophy have witnessed over the last century, there is one more quest which derives from the personal life of everyone and not only limited to scholars pondering upon (seemingly solely) academic problems: That quest is the quest the human spirit is "condemned to." This is the quest for meaningfulness. "Identity is the quest for meaningfulness" writes Charles Taylor who brought the idea of identity into a more conceptual domain than it was before the introduction of his work. We always stand in a relationship to others. "The very way we walk, move, gesture, speak is shaped from the earliest moments by our awareness that we appear before others, that we stand in public space, and that this space is potentially one of respect or contempt, of pride or shame” (Taylor, 15). The world looks different when seen from the standpoint of different social identities. Human beings and social relations appear in different shapes, assume different degrees of significance, and are classified and understood differently (Parekh, 24). The public space provides the "significant others" in the Freudian sense, and attributes meaning to movements, facial expressions which stand in communication with others to interpret, accent which in certain context mark educational and economic background are all constituents of this public space. So is political participation and deliberative politics.

Taylor argues that the self and the moral are in a close relationship. The quest is always a quest for meaningfulness, and identity has a lot to do with this. Searching for meaning, we do find ourselves attaching value to different components of our lives: be it work, family, taste in literature, or, as in the study of CP, country. Deconstructing the self and defining which identity to hold on to, in which context, is not a self-evident fact. The modern era makes one a mother, a writer, a fashion-addict, a political analyst, and a number of different persons all at the same time. An individual might have a number of different identities, according to Parekh. And given the different context, one chooses which "hat" to put on. It is a very general condition of social life, and of modern social life in particular, that nearly everybody should find herself wearing at different times a number of different hats-very often at one and at the same time with varying degrees of comfort or discomfort (Montefiore, 9). Among all these constituents of the self, as difficult as it may be to draw clear demarcation lines within the self in the abstract sense, the theory of CP singles out "national identity.” The multiplicity of identities, in Parekh's conception, has a positive side that is the capacity of one 
identity correcting the contours of another. While addressing national identity, CP seeks to bridge the gap between a cosmopolitan and a particularistic identity. The national and the universal coexisting together exemplifies the sought after way of dealing with the tensions between the particular and the universal as well as a number of different sources of meaning in one's life. Taylor criticizes the Habermasian idea of understanding identity in terms of a "proceduralist morality" and invites us to think of identity in completely new terms. Taylor's interpretation of Habermas, I argue, is correct but misleading as it overlooks the role national attachments play in CP. CP is a dynamic project which seeks to transform, improve and adjust national identities in light of universal ideals.

The multiplicity and juxtaposition of national identities reveals itself in the European project in the clearest way. At the time of writing of this article, there are European leaders delivering public statements about the Russian annexation of (now formerly) Ukrainian peninsula of Crimea. The European leaders try to reach a conclusion together in responding to the Russian President's decision. Seeking accord between the member states of the European Union, expressing themselves with one voice and taking decisions which are binding for all member states require a form of identity which is collective. The European nation-states expressing the European opinion in international relations do not, by its very definition, abandon their national identities. Neither do they give up any specific moral values embraced by their populations while making declarations about Crimea. They do, however, move closer to universal moral ideals such as Democracy, Human Rights and in this specific case, those of International Law. Identity is a challenging concept. How one defines oneself, based on which characteristic or background is a complex issue made simpler in the theory of CP by addressing national identities only, as much as these identities can be in juxtaposition to a number of other identities.

The European example of acting collectively, be it in the case of Crimea or Eurozone crises which come up often in Habermas's writings on Europe, demonstrates that state sovereignty has been breached long ago. Just like the national identity and distinctive national characteristics of these nation states which need not be abandoned, the national state-sovereignty need not be abandoned either. Sovereignty is the capability of a state taking decisions within its borders. In international relations, however, it is not clear who the main actor is in cases of collective decision making mechanisms. The G7, NATO as well as the EU demonstrate this collective expression in the international domain. International relations and transnational institutions refer to $\mathrm{CP}$ at the cosmopolitan and supranational types of CP. Placed within a national context, however, one can argue that the British Government taking decisions at the European level is already verbalizing the wishes of the democratic citizenry of its multicultural population. Therefore, $\mathrm{CP}$ understood as a process and a relation between different forms of identities exists both inside and outside the national public sphere. In "The Crises of The European Union,” Habermas argues that the sovereignty of the nation-states is "partially preserved” (Habermas 2012, 40). This derives from the right to exit that every state is given. By ensuring, in the legal form, that every nation-state can quit the union just like they joined it, the European Law preserves, the notion of national sovereignty. The end of March 2014 has witnessed two British political parties making statements about a possible referendum about the European membership of the British. This possibility of holding a referendum on the right to exit reminds the citizens of Europe as well as the UK that countries still maintain a level of independence and national sovereignty. Therefore, many seemingly different notions of Habermasian political theory tie together in the theory of CP taking its shape in the European context. 
After having introduced "the partially inscribed reason" in Between Facts and Norms, Habermas talks about two different paths of legitimation in Europe: one leading from national citizens to the negotiation mechanisms of the transnational entity among nation-states (regarding the global domestic affairs), the second one being the cosmopolitan citizenry relating to the peace and human rights policy of the world organization (Habermas 2009, 118). This world organisation is an envisaged one, without a correspondent in real political life right now. The closest example to it would be the UN. Europe as a project, according to him, needs to be visualized as having been cooriginally created by the peoples as well as the citizens of Europe. Construing citizenship and the peoples separately, Habermas argues that one will be able to consider Europe as a more democratically legitimated project. It is not only the different peoples of the nation-states of Europe which created the supranational project of Europe, but the citizens of those nation-states as the bearers of rights. The constitution of Europe symbolizes a common document on which citizens of different nation-states express their political will, albeit in an indirect manner: "From the perspective of a rationally reconstructed constitution-building process, the subordination under European law can be understood as a result of the fact that, from the very beginning, two different subjects were involved who cooperated in bringing about a supranational political community” (Habermas 2012, 28). The two different subjects involved in the European project which Habermas mentions are the national citizenry, and the cosmopolitan citizenry. This is nothing but re-imagining the self differently. A triple typology of CP offers a third component to this in contradistinction to both: That is the European citizenry (28). The national citizens, the European citizens and cosmopolitans (without possessing a status of citizenship for the time being) constitute a three level conceptualization of the “citizenry” deriving from Habermas's writings on Europe.

I argue that a typology of constitutional patriotism that distinguishes between the national, the transnational and the cosmopolitan would bring more analytic clarity to the concept of constitutional patriotism. In the way Habermas understands two different kinds of citizenry, both would be engaged in peace and human rights policy of the world organization. In this sense, moral agents use their ties to the national citizenry as well as their commitment to the universal human rights to ponder upon the implications of a cosmopolitan politics and engage with principles from Kohlberg's perspective, would emerge at the last stage of moral development. In Europe, Habermas argues for a concept of juridification which takes individuals and states as its starting point. In this sense, he places the attachments of individuals to states and of states to transnational entities in the heart of his conception of legitimacy. While his recent work on Europe offers two paths of legitimation in Europe, his political theory offers a two-track model of democracy:

Starting with the assumption that the normative validity claims of politics and law lack a cognitive meaning, such a theory attempts to explain how the individual interests of elites and citizens could nevertheless provide them with good reasons for making their contribution to the normatively demanded legitimation game of liberal mass democracies. If such a model of democracy could be justified, then our question concerning the external relation between the facticity and validity would, quite elegantly, become pointless. (BFN, “Deliberative Politics,” 291)

Therefore, the cognitive meaning which normative validity claims of politics and law are missing is inherent in the different sections of the society. The citizenry as the holder of these interests and opinions comes to participating in the legitimation of mass democracies. In this sense, the cognitive attitude the citizens have in deliberative politics is a core, but yet underemphasized component, of a two track model of democracy advocated by Habermas. The national citizenry as the source of legitimacy obscures the way in the formation of transnational or cosmopolitan identities. By addressing the nationalistic feelings of citizens and subjecting them 
to yet another normative process of increasing level by level on the stages of moral consciousness, CP brings duplicity in deliberative politics and legitimacy together. Habermas's writings on Europe call for two different conceptualizations of the relationship citizens have to the sovereign: one from citizenry to the supranational (or cosmopolitan) entity, the other from citizenry to the national entity.

The duplicity in conceptualizing citizenry (the one which already exists) and an alternative way of looking at the world politics from a philosophical point of view, according to Habermas, entails lowering the threshold between international and national law (Habermas 2012, 67). The European Law, as it stands above the national law in certain policy areas, exemplifies the international law. Rendering the national and the international law more similar and responsive to each other fits into the purposes of CP regarding multiple identities; that is one identity correcting the contours of another. The national law embracing the principles of international law corresponds to the idea of loving the world citizens on the merit of them being human despite being from different "circles of the self." Two strands of legitimation proposed by Habermas for Europe are the national and the transnational citizenry and three different models of law are the European, the national, and the international law. A third level of governance he proposes in The Crises of the European Union is a world government which is above the nation states and unions of states. Each level of government, in this design, requires different strands of legitimation (Habermas 2012, 68). His earlier works on Europe as well as his recent writings refer to the concept of a world government directly: A legal embodiment of universalistic standards of justice needs to assume the character of a state for the constitution to function effectively (Habermas 2009, 117).

\section{The Transformation of European Public Sphere and CP}

For a better functioning and more democratic European Union, there should be more participation in European politics and more exchange between different European national public spheres. This call for developing informed opinions in the European as well as the cosmopolitan functional public spheres necessitates a framework of constitutional patriotism. Habermas does not, however, place the argument about a dual citizenry in the framework of constitutional patriotism and political affect. The patriotic feelings of citizens and the meaningfulness their particular attachments address this integral component of a legitimation for world society that Habermas does not initially bring forth. Therefore, Habermas introduces a fine balance between particularism of attachment and universality of normative moral principles at the global level in such a way that the particular (national and cultural attachments) of citizens that constitute their different world views would be delimited with fair boundaries between national and cosmopolitan solidarity. In Europe, Habermas refers to the question about the moment which the particular duties of national governments toward their own citizens based on shared national identities must take a back seat to the universal legal obligations which all the states incur towards cosmopolitan citizens of international community. He presents this as an unresolved tension, and it is the tension on which constitutional patriotism is built. Constitutional patriotism, defined by Jan Werner Muller as a dynamic and on-going project, derives from this tension. This characteristic of CP, being dynamic and on-going, makes it difficult to draw demarcation lines between identities of different kinds: Where does national identity stop and is diluted into the cosmopolitan identity? This is a question which will be left to various contextual political interpretations due to the space concerns of this work.

After having written BFN with references to the partially inscribed reason and referring to the existing practices in his political writings, Habermas then argues in Europe that the cosmopolitan citizenry needs to go 
through a "learning process." I argue that the moral development of the cosmopolitan citizenry in CP equates to this learning process which he brings up in his more recent work. In Europe, he brings into light that the cosmopolitan citizens take their orientation from universalistic standards which address international peace and human rights. Juxtaposition of his arguments in Europe with respect to the universal moral standards by which the cosmopolitan citizenry abide emphasizes the issue of the directionality of Kohlberg's moral development in his political theory. The abstract object of universal ethical principle orientation, I argue, derives from the constitution as an embodiment of universal moral principles. The constitution stands in the place of the object of attachment at the last stage of moral development in CP. The last stage of moral development as it was originally developed by Kohlberg and also by Habermas in Moral Consciousness did not refer to this abstract object as the constitution itself. The element Habermas introduces at the sixth stage of moral development that is the social contract is transformed into a universal constitution in the theory of constitutional patriotism. In this sense, reading Kohblerg's and Habermas's accounts of the moral self into constitutional patriotism points to a cosmopolitan citizenry.

\section{The Role of Reason in the European Public Sphere}

Constitutional Patriotism as understood by Muller, Cronin, Soltan, Abraham, and Ingram is a theory. Nowhere in Habermas's writing, we find the terms "constitutional patriotism" and "theory" together (in the English translation). He does, however, have an argument about how theories should be built: When it comes to theory building, we must take historical developments into account, Habermas argues. Clinging on to a state-centered tradition of modern political thought deprives us of the tool of focusing on the citizenry which, in Habermas's writings on Europe, emerges as the source of legitimation. Construing a cosmopolitan ideal at the "right level of abstraction" as he puts it allows the political theorists to make use of patriotism understood in the national sense. A high level of abstraction and pure reason at the global level which derives from the "partially inscribed reason" implied in the social facticity construes a legitimation of universal ideals with a sense of applicability in the political domain.

The Crises of the European Union, the book as well as the recent crises, holds much more than expected for the theorization of CP. It spans over a number of concepts which the theory of CP understood by the currently existing literature addresses; ranging from reason, legitimacy to democracy. The role of partially inscribed reason in the theory of CP takes one more alternative shape in light of The Crises of the European Union. Habermas refers to reason and enlightenment in the Kantian sense and seeks to place this within the domain of the European public sphere: "Liberation from self-incurred tutelage meant Enlightenment. With regard to the individual, this denoted a subjective maxim, namely, to think for oneself. With regard to humanity as a whole, it denoted an objective tendency, progress towards a perfectly just order” (Habermas 2012, 104). A transformation towards a new understanding of the self, to be able to think for oneself as an individual or as a collectivity is understood as a process. This process, understood as progress towards that which is accepted to be better hence normative, is a movement aiming at a perfectly just order. This is an attitude political science and international relations lack-as academic disciplines as well as practice. Moral Consciousness and Kohlberg's interpretation by Habermas holds that this progress, I argue, aims at a legal orientation. By referring to humanity as a whole, Habermas hints at his cosmopolitan tendency. Robert Fine and Will Smith interpret Habermasian cosmopolitanism as a quest of breaching Kantian theory of cosmopolitan right with our time. The rational content of a nationally constituted political community has the advantage of rendering legitimation and 
political deliberation easier in the public sphere. The idea of cosmopolitanism and advocating world governance for the humanity on the whole has another reason behind it: That is the well-being of everyone, not just the members of a given nation state. An economic reading of game theory would suggest the well being of highest number of people possible. Building itself on the normative pillars of Human Rights as well as of that of Democracy, the theory of CP restricts its scope of feasibility to a large extent. Letting go of Democracy, for example, would have made it much easier to defend universal moral ideals of (or and) human rights. Nowhere in the literature has CP been detached from Democracy so far. And doing so would lead to a totalitarian regime in the form of a world governance. The identity of world citizens would encompass and maintain the particular(istic) national ties of the nation-state level only if the rationality of nation-states can overlap with the rational content of the cosmopolitan project (Fine 2003, 470). To attain this, I argue, we need to read the theory of CP not only with democracy, citizenship and human rights but also in the European context. The reason that any single individual may attain and free herself from tutelage is difficult. It is, however, easier to aim at a transformation at a broader level, Habermas argues: "That the public should enlighten itself is more possible; indeed, if only freedom is granted Enlightenment is sure to follow" (Habermas 2012, 104). Habermas challenges Kantian reason and Enlightenment. As always, he has an optimistic reading of history and believes that Enlightenment does not need to result from freedom but it can also lead to freedom. Not every single individual may attain Enlightenment if she tries by herself, perhaps. The society as a whole becoming free, on the other hand, can lead to using freedom in a positive sense and attaining Enlightenment. Habermas's approach to the national public sphere as well as his approach to a supranational and cosmopolitan public spheres bears the same connotations.

The dual nature of two different paths of legitimation in Europe means that national politics does and probably will continue to recede behind the European decision making mechanisms. The much debated superiority of European institutions over national parliaments in international decisions means a superiority of the right over the "good," the subsumption of politics under morality. A collective decision making mechanism is, by definition, more fair than an individual and possibly selfish attitude bearing the well-being of the self, or that of the nation, above others. Europeanization is a step, on the steps of Kohlberg, towards a cosmopolitan order of world governance. The subsumption of the national governments under European institutions means the subsumption of politics under morality (Habermas 2012, 164). Legality, on the other hand, would follow from morality. Therefore, CP defends a transformation of the national public spheres in the name of moral principles and an embodiment of these in a legal document. This, however, is in contradiction with a point I have developed before: presuming that Enlightenment does not need to result from freedom but may also give rise to it does not demonstrate clearly where law fits in this schema of freedom and enlightenment. Understood in the conventional sense, freedom would lead to enlightenment and not vice versa. By reversing this equation, Habermas reflects his normative tendency. The European constitution is fit for this purpose as it has been created by the elites and not by the peoples themselves (Habermas 2012, 30). As much as it may lack democratic backing if democracy is understood in the conventional sense, the European constitution is an example to a legal orientation placing the rationale of the supranational institution above the national ones almost in an imposing and normative manner. An individual or a society may find Enlightenment even if freedom is initially imposed upon them, he seems to be claiming. He does not think of freedom as a dress which needs to fit well on the social self for it to look good: freedom, for Habermas, is a joker which fits every context and necessarily leads to good results. For Kohlberg and CP, law needs to be the last stage which 
universal sense of morality leads to. Without a legal document as the object of attachment, it is unclear how CP might reform a new form of attachment based on the constitution of a country. Conceiving the main object of attachment as the political liberal culture which then leads to legalisation may facilitate the predominantly psychological discussion about the object of attachment in CP.

The double nature of the tracks of legitimation and of conceptualizing the citizenry is supported by a mutual trust among the European peoples that with increased interest in the affairs of each other, there will be a stronger collective hence European identity. Habermas wishes for a form of "civic solidarity" to arise in this supranational sphere (Habermas 2012, 29). Developing a justice perspective broader than the national one is a burden falling onto the European citizens. The Europeans would have to decide which part of their now more permanently multiple identities to hold on to in different cases: the perspective of a European citizen or that of a member of a particular nation (Habermas 2012, 37). This division of identities is not meant to render the identity construction on the individual level more difficult. Rather, as I interpret Habermas from the perspective of $\mathrm{CP}$, it is meant to facilitate the juggling of different roles and perspectives one might find oneself possessing (or wishing to possess). Nussbaum's conceptualization of the self in the form of concentric circles suggests that one should make the effort to get to know the unknown and unfamiliar in order to become a better person. This philosophical attitude, however, does not illuminate questions from a governance perspective: National identities make people feel like they are the members of one nation and not another. Accepting that embracing the values of others as well as that of the self and caring for the originally unfamiliar, the most external circle of the self, is a good thing; how is one to implement this in international relations?

The democratic deficit of the European union can best be addressed by a change of perspective which can take place now: The dual approach to the citizenry invites the observers and scholars to conceptualize the European citizenry in an analytic light which looks at the entirety of the European population, including all of the member states, and distinguish between the different roles the same citizenry has. Citizens ought to develop the skills to think of the benefit of their nation-states as well as that of the EU. Being EU citizens and members of different nation-states can, in this conceptualisation, coexist in the selfhood of political consociates (Habermas 2012, 37). Habermas proposes a scenario in which the national attachments will be "extended" (Habermas 2012, 46) without being annihilated or abandoned in any way. This extended particularistic self is more abstract and less resilient, civic solidarity shared by all member-states. This definition of the European citizenry sharing an abstract and civic form of solidarity is akin to the definition of CP defined in broad terms. Without referring to the concept of CP per se, Habermas's invitation to reconsider the European solidarity has a large space of overlap with Muller's theory of CP. Only in the case of a dual conceptualization of the citizenry with emotional ties of the citizenry to two different levels of governance, Habermas argues, can the parliament in Strasbourg develop the ability to participate in a joint process of will-formation reaching across national borders.

Expanding the networks of communication which exist within the national sphere has a political dimension which favors liberalism. While seeking to relate to other national spheres, Habermas advocates the preservation and betterment of liberal "values and attitudes" and an inclusion of the strangers. Including immigrants into the societies is not any different from improving the social cultural skills about relating to different societies and communities: Expanding the national publics sphere so as to address the inner political and social issues of other European member states requires the same expansion of the innermost circle of the self as the collective external national self expanding and reaching out to another national sphere. Therefore, 
Habermasian CP defines how to bring Nussbaum's conceptualization of the self taking its cue from the Stoics into the much debated concept of the national self from cosmopolitan and multicultural perspectives. Understanding that which is different, and speaking in another language, is the best way to relate to other societies. Anthony Giddens argues that speaking in another language is the best sociological tool for broadening the social scientist's perspective. Habermas refers to perspective and identities in his work on Europe more than anywhere else in his work. National identities which are "strong identities" pose an obstacle before this self-enrichment for him. The strong identities, which in some contexts are more at place than others, need to be stimulated through legal institutional means.

An observation of Habermasian theory as a whole gives different insight to multiple aspects of CP; to that of law in particular. The fact that the theory of CP seeks to re-establish political identity in light of law and universal moral norms is not a coincidence: a broad study of Habermas's work justifies the reason behind this. Political identity in the age of nation-states being part of shared political and cultural attitudes and convictions, on the one hand, and the universal ideals sought by CP, on the other, mutually reinforce one another. Just like politics and law interact with one another, they in turn react with the shared political and cultural attitudes. The legal and social interaction, according to Habermas's writings on Europe, is not solely about a legalistic process of law-making but about the norms and values embedded in a legal format; that is the constitution itself (Habermas 2012, 46). A European constitution, therefore, is the centre point of a European CP.

Legality as a significant component of CP derives from (or relates to) Habermas's interpretation of law: Law has the tension between facticity and validity built in itself (BFN, 390). The way to solve this tension inherently built into law is possible by justifying the legal authority by all the participants. The "cognitive meaning" which a normative theory of politics and law lack adds the emotions and decisions of the citizenry into the political and legal procedures. In BFN, in the chapter on Deliberative Politics (BFN, 291) and A Reconstructive approach to law, he argues that the tension between facticity and validity can be solved by justifying the "normatively demanded legitimation game of liberal mass democracies." The Crises of The European Union and CP fit into this as it seeks to establish the role of the citizenry in the legitimation process from a point of view addressing "identity." Politicians in Europe and in the world are seeking ways to establish mechanisms capable of "transforming mentalities" (Habermas 2012). The need of transforming mentalities at the European level has been discussed in Habermas's earlier work on Europe as well as his more recent one: Regarding a reform treaty, he wrote that despite a reform treaty and a constitution are productive steps towards a stronger collective identity (which he views in a positive light), it leaves the mentality of European citizens and their participation in the European public sphere completely unaffected. CP proposes this mechanism of mental transformation about the feelings of the citizenry (Habermas 2009, 79). By addressing the mentalities and utilising the tool of participation in the public sphere, it relates to seemingly different aspects of Habermasian theory on the whole. Participation of the European national public spheres in the affairs of one another and becoming more responsive to issues which human beings, irrespective of their national status, can relate to not only the post nationalism and cosmopolitanism of Habermasian theory involved in it; but also is reminder of the Theory of Communicative Action and the Structural Transformation of the Public Sphere. For now, I would like to restrict myself to highlighting his call for Europeans as a means to situate the theory of CP in an empirical setting: "For, until the usual spectrum of opinions and relevant issues within the national public spheres is broadened and until the public spheres become responsive to one another, the citizens derive no benefit from a formally strengthened status of the parliament” (Habermas 2009, 81; 87). Broadening the 
spectrum of opinions from within a national perspective to address those who belong to different nationalities is part of the theory of CP. Habermas singles out multilingualism as the most significant obstacle before this post-national communicative action. While not referring to CP in the chapter of "The Plea for a Graduated Integration” in Europe in 2009, Habermas does, however, refer to a notion of CP in the same work, in another context:

The development of a European "identity" can be understood as the continuation of a process which is already taking place within some of the member-states. In response to challenging historical experiences, and as immigrant groups who maintain ties to their countries of origin become culturally and politically integrated, there are already initial signs of a properly understood constitutional patriotism as a basis for civic integration within these states. (Habermas 2009, 129)

Constitutional patriotism as a basis for civic integration, therefore, is an umbrella term for a number of institutional, legal, and bureaucratic changes taking place in modern Europe. In contemporary politics, European Commission provides a good case in point example for the transformations regarding civic solidarity as Habermas understands it: The different sections of the European Commission, such as the section responsible of enlargement, seek to "transpose"- the national law into the European law and implement the European law in the countries of which are still to join European Union and which recently have joined it. This shows how in practice abstract universal ideals are intertwined with law and find their place in implementation. Habermas claims that there already is a sense of CP in Europe not because of the implementation and enforcement of European Law at the national level but because within the nation states there are groups which maintain ties to their countries of origin while participating in the liberal political culture of the host country. Therefore, the CP which already exists exemplified by Habermas in 2009 was construed at the national level while his later work on Europe (The Crises of the European Union) has evolved in a way to condor European Union itself in light of CP. The immigrant groups Habermas had referred to in 2009 would be negotiation between two kinds of identities which are both national: their home country and their host country (presuming that they come from a unified nation-state). The negotiation process between different forms of identities within the boundaries of the same political and moral self would be addressing two national identities only. This bargain between two similar types of identities, albeit the possibly different levels of acquaintance with participation in liberal forms of thinking, I argue, is different from what a full account of CP holds: CP is best understood as a process between nationalism and cosmopolitanism. Muller has successfully placed it in this philosophical spectrum in the most distinct way. CP as an in between concept between nationalism and cosmopolitanism, between particularism and univeralism, therefore, does not fully overlap with one of the very few direct references Habermas makes to it. Habermas revisits the themes of universalism and particularism often in his political theory. A close examination of his work on Europe demonstrates a contradiction between different constitutional patriotisms he has in mind or point to a possible transformation in his thinking (either about the concept of CP itself or his broader account of the possibility of implementing universal moral ideals in particular concepts).

The Crises of the European Union holds that there isn't only need for strengthening the European solidarity but that "the international community of states must develop into a cosmopolitan community of states and world citizens.” Therefore, the internationalism aspect of the CP, that is the second type of CP, needs to expand one more time to reach the cosmopolitan level. Habermas expresses this need for legalized world governance and a world citizenry to support it. The European Union has enjoyed a "civilising role" which 
managed to bring post-war societies to a diplomatic and economic path. This role that Europe enjoys will become more prominent when it is considered in light of a "more far-reaching cosmopolitanism." Europe can be more active as a collective entity in international relations, rather than solely seeking the political integration and the economic benefit of its citizens, but act and represent itself in international relations and via foreign policy. It is decision-making in foreign policy which requires autonomous thinking and acting.

Critics of CP argue that it is too abstract an idea to take hold in the emotional lives of the citizens. Communitarians as well as liberals thus misconceive national identity: National identity came to existing in the 19th century of Europe and has a floating character. There is nothing inherent in the quality of being human in the biological sense turning us into French or Afrikan. Birth is an arbitrary act. The abstraction of national identity can and should be coupled with other, even more abstract universal ideals for the betterment of society. The boundaries between nations and citizens of those nations are not given: Political community is a concept created by human beings and as their history changes, so do their needs and solutions they find for the problems in which they find themselves. "Loyalties evolve and traditions change. Nations, too, just like all other comparable referents, are not natural facts, even if they are generally not merely fictions either” (Habermas 2012, 47). While the constitutional definitions of nation-states and their subpopulations evolve and change (as the case of Crimea in our time demonstrates), their need for democratic legitimacy unmistakably results from having a horizontally integrated association of legal consecrates. Belonging and emotional ties to the notion of nationality are perhaps seemingly less abstract than universal moral ideals sought by cosmopolitans. It is hard, after all, to find people who are willing to kill and die in the name of Human Rights for all, or for Democracy. But the French Revolution proves that these ideological constructs take historical form and shape throughout time while the conditions need to be mature. Habermas, by referring to the French Revolution as an exemplar in changing and transforming identities, brings Marxist resonances into the theory of CP. Just as in the French Revolution conditions were mature for social forces and popular need to push legislation and politics into a different direction, so does in the case of a conceptualization in the Marxist understanding or the need for another form of political attachment in our time. Therefore, CP is part of critical theory in a distinct manner.

The changes in the social and political affairs of the world today point towards cosmopolitanism and universalistic morality. Most of the issues in which there is no transcultural consensus about the right value judgment are diluted into the social domain. This gives a seemingly de-politicised view of the cultural conflicts and conflicts in international relations. The different cultural practices among different cultures are judged exclusively from a moral point of view. "We are inherently familiar with everyday situations in which we feel obliged to show solidarity with strangers, with everything that has human face, without any hint of self-assertion. Only in this moral universe of all persons acting responsibly no one is excluded" (Habermas 2012, 64). The universalistic morality, in which individuals and cultures seek to reach value judgements, is the only medium which social values are translated into law (65). Human Rights, in this sense, is different from Democracy as one of the normative pillars of CP because it seeks to address every human being by the virtue of being human; irrespective of the form of governance one may prefer or find oneself obliged to live under. While Muller defines and limits the pillars of CP to Human Rights and Democracy, Human Rights plays a much more vital role in facilitating ease of reaching the inner lives and attachments of individuals living in different cultures and regimes, be it democratic or not. Universal morality is implied in Habermas' conception of world governance in the sense of military intervention too: Nation-states need to lend their military forces at the supranational level for enforcing the peacekeeping and human rights policies which they would be involved 
in designing. Having responsibility and a right to participate in the writing of universal law to apply in every corner of the globe, nation-states enjoy the right as well as carry the burden of taking part in cosmopolitan world governance. It is only the Human Rights policies, according to Habermas, that legitimately require national participation in extraterritorial jurisdiction. The D principle Habermas clearly defines in the BFN finds its place in this definition of a cosmopolitan community deriving from Habermas's writings on Europe: "Just those action norms are valid to which all possibly affected persons agree as participants in rational discourse,” the D principle holds. The implementation and enforcement of Human Rights at the global level deserves and requires the participation of all the nation states as participants in building these laws before being responsible with their implementation. Rational discourse which can take place at the diplomatic level in the process of law-making (if the currently existing Human Rights law and International Law are to be amended at all) among all the participants lead to the "action norms" in international relations to rightfully intervene and implement peacekeeping. The Crises of the European Union, in this sense, exemplifies some of the most abstract principles of Habermasian theory bringing a utopia one step closer to the real world.

Bridging the gap between facts and norms is thus facilitated by the existence and preservation (and perhaps a possible betterment) of the EU. This role Europe plays in Habermas's thinking is not only an important step-stone for bringing utopia closer to the world and vice versa but is also an important argument about how to make the cosmopolitan dream real: The EU can be understood as an "important stage along the route to a politically constituted world society," Habermas states clearly (5). It is, in this sense, not an end in itself but a stage for a long-term goal that either a revolution or a teleological interpretation of history holds. A global governance, beyond being tied by moral ideals in a legal format, needs to be "politically constituted" for Habermas. "The rhetoric of human rights have in fact exercised global effect over the past couple of decades" already (5). Conceptualizing a world society which is politically constituted looses something of its semblance of utopianism when we remember that not only human rights have enjoyed global scope in international relations and legal implementation of universal values albeit to some extent, but also that French Revolution has caused the distinction between civil and human rights to evaporate. Equal rights for all the "citizens" of the Republic have been acquired via the French Revolution. The political constitution of a world society (in addition to a moral one), from the perspective of CP, shows us the place we can find for the nation-states and national attachments of our age. Despite the utopian nature of globally implemented Human Rights, the experiences of violated human dignity foster a militant outrage which lends repeated impetus to the hope for a worldwide institutionalization of human rights. Critics who argue that CP is unlikely to take hold in any society, or that it is too abstract in nature would hardly contest the equally, if not more, abstract nature of the concept of human dignity - the violation of which finds legal therefore concrete reverberations. Law, in that sense, and Human Rights in particular, promise a domain in which the political and the philosophical can be expressed as well as protected together.

The D Principle applied at the global level requires that the transnational negotiations would be conducted within the notion of justice which the world parliament continually adopts itself to the duties laid down by Human Rights. In this sense, Habermas's reference to the world parliament has resonances of cosmopolitanism in it. Pushing itself away from nationalism and closer to cosmopolitanism, CP makes use of Human Rights and democracy as the most helpful tools along the way. A better understanding of how one needs to interpret democracy in the Habermasian sense, however, is beyond the purpose of this article. For now, I will limit myself to arguing that this democratic understanding as a normative pillar on which $\mathrm{CP}$ is built has 
discourse-theoretic connotations making Habermas's understanding of democracy all the more interdisciplinary and rich. Habermas trusts the "power of good arguments" winning in the international as well as within the national domain. CP holds that the D Principle implemented at the cosmopolitan level is optimistic (or one might say wishful thinking) about the values embedded in the Human Rights deriving from all the participants as representatives of different nation-states. The subsumption of national law to European Law, in some sense, facilitates the conflict resolution in writing Human Rights by all the participants-albeit in a normative manner. Europe in this way demonstrates how one form of law can be rendered superior to another while the contents of the former are subject to continuous scrutiny and interpretation.

\section{Popular Sovereignity as Procedure and CP}

Habermas demonstrates his preference for intermingling many seemingly different political, social, legal, and philosophical concepts one more time in the chapter of Between Facts and Norms dedicated to a conceptualization of sovereignty as procedure. Thinking about the role the French Revolution played in a legal as well as a sociological terrain about identity creation comes to the front in this chapter of the BFN. The French Revolution ties together eloquently the question about transformation of mentalities and citizens as right bearers in a common (national) sphere. French Revolution occupies large space in the minds of French citizens and in their "collective memory." Habermas criticizes the criticism of the two French intellectuals who have written about their "own" historiography claiming that "the clocks of collective memory keep different time in France and Germany” (BFN, 464). Different interpretations of the Revolution have determined the French nation's self-understanding. Habermas puts the French Revolution under scrutiny as a tool for the transformation of "mentalities:" The mentalities which were the subjects of a kingdom, once upon a time, who came to understanding themselves as fellow members of a nation, need to be transformed one more time for another collective self-understanding, his CP would hold. "The needs for orientation" of the present time can be satisfied with the study of 1789 as a historical turning point. His work on The Crises of the European Union and insistence on maintaining the political bonds in Europe despite much economic problems which have been faced exemplify one collective mental transformation he seeks. His references to the French Revolution in BFN as well as in Europe (subtitled "The Faltering Project" in 2009) is one dimension of the CP I construe. The second typology of CP, that is CP as supranational identity, thus finds a distinct face of its own when placed between the Political Theory and Political Writings of Habermas; between his ideals and examples from the real world.

The needs for orientation and history gaining momentum through spinning itself over a moment in time acquire an almost positive scientific terminology in Habermas's approach to sovereignty and national identity: The French Revolution "accelerated trends that were already under way," he writes. The projection of a stronger European solidarity is also underway, for him. In this sense, without the "orienting power" of the French Revolution, the political and social circumstances of our day are in many ways similar to those of 1789 : The latter had resulted in a legal expression and a new form of collective identity that came to being associated with the core of nationalism. In CP, the "abstraction" of the ideas before 1789 and their impossibly intertwined nature to the political selves in the age of nation-states needs to be implemented at the right balance between facts and norms, between real and ideal, and between universal and the particular.

The interdependence of world political affairs today, a popular sovereignty "as a procedure” and national 
"consciousness" come together in the example of Europe in BFN: "The contemporary heirs of the European system of states, having taken nationalism beyond its limits, find themselves on the path to a post national society" (BFN, 1998, App. I, 465). Habermas did not read Kohlberg or moral consciousness from the perspective of nationalism, despite that he argued for embracing universal principles in the form of law at the last stage of moral development. In BFN, he adds "national" to his understanding of "consciousness" and its empirical example in the real world, here in our time, in Europe. The social integration in the form of a national identity which came true with the French Revolution is that which we need, for a European solidarity, through a social integration using different historical moments in time but similar conceptual tools: such as the collective memory, law, citizenship and national (or European) consciousness.

\section{Works Cited}

Arendt, Hannah. Origins of Totalitarianism. London: A Harcourt Book, 1976.

Cronin, Ciaran. “Democracy and Collective Identity: In Defence of Constitutional Patriotism.” European Journal of Philosophy 11.1 (2003).

Giddens, Anthony. Emile Durkheim: Selected Writings. Cambridge: Cambridge University Press, 1972.

Habermas, Jurgen. The Theory of Communicative Action: Reason and the Rationalization of Society. Cambridge: Polity, 1984.

---. The New Conservatism. MA: MIT Press, 1989.

---. The Structural Transformation of the Public Sphere. Cambridge: Polity, 1989.

---. Moral Consciousness and Communicative Action. Cambridge: Polity, 1990.

---. Communication and the Evolution of Society. Cambridge: Polity, 1991.

---. Postmetaphysical Thinking. Cambridge: Polity, 1992.

---. Justification and Application. Cambridge: Polity, 1993.

---. A Berlin Republic. Nebraska: University of Nebraska Press, 1997.

---. Between Facts and Norms. Oxford: Blackwell Publishers, 1998.

---. “Concluding Comments on Empirical Approaches to Deliberative Politics.” Acta Politica 40.384 (2005).

---. Europe: The Faltering Project. Cambridge: Polity, 2009.

---. “The Concept of Human Dignity and the Realistic Utopia of Human Rights.” Metaphilosophy 41.4 (2010).

---. The Crises of the European Union. Cambridge: Polity, 2012.

Hunt, Lynn. The French Revolution and Human Rights. Massachusetts: Bedford/St. Martins, 1996.

Fine, Robert and Smith Will. “Jürgen Habermas’s Theory of Cosmopolitanism.” Constellations 10.4 (2003).

Fine, Robert. Cosmopolitanism. London: Routledge, 2007.

Kohlberg, Lawrence. The Philosophy of Moral Development. New York: Harper and Row, 1981.

Kleingeld, Pauline. Kant and Cosmopolitanism: The Philosophical Ideal of World Citizenship. Cambridge: Cambridge University Press, 2013.

Mead, George Herbert. Mind, Self and Society. London: University of Chicago Press, 1934.

Montefiore, Alan. A Philosophical Retrospective: Facts, Values and Jewish Identity. Columbia: Columbia University Press, 2011.

Muller, Jan-Werner. Another Country. New Haven and London: Yale University Press, 2000.

Muller, Jan Werner. Constitutional Patriotism. New Jersey: Princeton University Press, 2007.

---. “Three Objections to Constitutional Patriotism.” Constellations 14.2 (2007).

---. “A General Theory of Constitutional Patriotism.” International Journal of Constitutional Law 6.1 (2008).

---. Contesting Democracy. New Haven: Yale University Press, 2013.

Nussbaum, Martha. For Love of Country: Debating the Limits of Patriotism. MA: Beacon Press, 2002.

---. Love's Knowledge. Oxford: Oxford University Press, 1990.

Okin, Susan Muller. Is Multiculturalism Bad for Women? New Jersey: Princeton University Press, 1999.

Schwartz, Alexaner. "Patriotism or Integrity? Constitutional Patriotism in Divided Societies.” Oxford Journal of Legal Studies 31.3 (2011).

Specter, Matthew. Habermas. New York: Cambridge University Press, 2010. 
Taylor, Charles. Multiculturalism. New Jersey: Princeton University Press, 1994.

---. Sources of the Self: The Making of the Modern Identity. Cambridge: Harvard University Press, 1992.

Viroli, Maurizio. For Love of Country: An Essay on Patriotism and Nationalism. Oxford: Oxford University Press, 1993. 